Revista Colombiana de Obstetricia y Ginecología Vol. 56 No.2 • 2005 • (180-184)

REPORTE DE CASO

\title{
ABSCESOS MIOMETRIALES MÚLTIPLES. CASO CLÍNICO Y REVISIÓN DE LA LITERATURA
}

Multiple miometrial abscesses. Clinical case and literature review

Edith Ángel, M.D. *, Lilia M. Sánchez, M.D.**

Recibido: abril 12/2005 - Revisado: junio 17/2005 - Aceptado: junio 27/2005

\section{RESUMEN}

En este artículo se informa un caso y se revisa la literatura acerca de los abscesos miometriales. Se presenta el reporte de una paciente primigestante, quien presentó infección uterina en el puerperio temprano.

Pese al manejo con antibióticos, la respuesta clínica no fue adecuada, persistiendo los signos de respuesta inflamatoria sistémica.

$\mathrm{Al}$ examen pélvico y ecográfico se encontraron masas anexiales. En el decimoséptimo día se realizó laparotomía, encontrándose múltiples abscesos miometriales y celulitis pélvica, sin masas anexiales. Se realizó histerectomía total y se continuó el manejo antibiótico, con evolución postoperatoria satisfactoria.

Se presenta una revisión de la epidemiología, el cuadro clínico y la clasificación de la infección puerperal.

Palabras clave: infección puerperal, endometritis, miometritis, abscesos miometriales, celulitis pélvica, histerectomía.

* Ginecóloga-Obstetra. Docente Facultad de Medicina, Universidad Nacional de Colombia. Correo electrónico: eangelm@unal.edu.co

* Patóloga. Docente Facultad de Medicina, Universidad Nacional de Colombia.

\section{SUMMARY}

In this article a case and a review of the literature about miometrial abscesses are reported. The patient was a young primiparous woman who presented a puerperal infection. Despite the antibiotic treatment, the clinical status of the patient worsened progressively and signs of systemic inflammatory response persisted. An adnexial mass was founded in the pelvic examination as well as in the ultrasonography.

A laparotomy was practiced at the seventeenth day of puerperium, finding multiple miometrial abscesses and pelvic cellulitis without adnexial masses. Hysterectomy was practiced and treatment with antibiotics was continued. The PO evolution was satisfactory.

We discuss the epidemiology, clinical manifestations and classification of the puerperal infection.

Key words: puerperal infection, endometritis, miometritis, miometrial abscess, pelvic cellulitis, hysterectomy.

\section{RESUMEN HISTORIA CLÍNICA}

Paciente de 16 años, G1P1, quien el 8 de julio de 2002 presentó parto eutócico sin complicaciones en un hospital de segundo nivel de Bogotá.

Consultó al séptimo día del puerperio, por dolor abdominal, tipo cólico de 3 días de evolución y temperatura de $39^{\circ} \mathrm{C}$. 
Se diagnosticó endometritis puerperal y se inició tratamiento antibiótico. Al segundo día, fue remitida al Instituto Materno Infantil por respuesta inadecuada.

Los hallazgos al ingreso fueron tensión arterial de 140/90, frecuencia cardíaca de 100 x minuto, frecuencia respiratoria de $30 \mathrm{x}$ minuto, temperatura de 38,3 ${ }^{\circ} \mathrm{C}$, saturación de oxígeno de $86 \%$, deshidratación leve e hipoventilación sin signos de dificultad respiratoria. Ruidos cardíacos taquicárdicos con soplo holosistólico grado II/VI en mesocardio y desdoblamiento fijo de S2. Se encontró abdomen blando, depresible con dolor a la palpación en flanco y fosa ilíaca derechos.

Al examen genital se encontró episiorrafia dehiscente sin signos inflamatorios locales, vagina elástica, normotérmica, cuello posterior permeable un dedo, no doloroso a la movilización. El útero medía $16 \mathrm{~cm}$ y se palpó una masa parametrial derecha dolorosa de $5 \times 5 \mathrm{~cm}$. El aspecto de los loquios era normal.

Los paraclínicos de remisión incluían una ecografía pélvica normal, cuadro hemático $(\mathrm{CH})$ con hemoglobina de $8,0 \mathrm{~g} / \mathrm{dL}$, sin leucocitosis, pero con granulaciones tóxicas en los polimorfonucleares, proteína C reactiva (PCR) elevada $(519 \mathrm{mg} / \mathrm{dL})$ y parcial de orina compatible con infección urinaria.

Los diagnósticos de ingreso fueron: puerperio de 9 días, sepsis de origen obstétrico, endometritis posparto en tratamiento vs. miometritis, parametritis derecha, y trombosis del infundíbulo pélvico derecho.

Se inició manejo con cristaloides, esquema de gentamicina y clindamicina, heparina a $1.000 \mathrm{U} /$ hora y $\mathrm{O}_{2}$ al 35\%. La radiografía de tórax mostró aumento del índice cardio-torácico, con líquido en la cisura y redistribución del flujo hacia los ápices. La paciente presentaba oliguria.

Se diagnosticó disfunción ventricular, por lo cual se colocó un catéter central, se digitalizó y se inició inotropía con dopamina a $5 \mu \mathrm{g} / \mathrm{kg} / \mathrm{min}$. A las dos horas, la paciente presentó mejoría de la diuresis (200 mL/hora).

El CH de ingreso mostró leucocitosis y anemia y se encontró hematuria. Se practicó transfusión y se cambió esquema a ceftriaxona más metronidazol. La ecografía pélvica mostró útero de 16 x 7,3 x 10,8 cm con endometrio lineal de 11 $\mathrm{mm}$. En el anexo derecho se observó una masa de ecogenicidad mixta con bordes mal definidos de 7,3 x 5,2 cm de diámetro, que sugería absceso tubo-ovárico.

Dos días después del ingreso ocurrió un pico febril, se observó dolor a la palpación profunda en hipogastrio y fosa ilíaca derecha, se encontraron loquios fétidos y el balance de líquidos fue negativo. Persistió leucocitosis $\left(16.500 / \mathrm{mm}^{3}\right)$ con neutrofilia (81\%) y PCR elevada $(104,1 \mathrm{mg} / \mathrm{L})$. Al sexto día presentó un nuevo pico febril $\left(38,6{ }^{\circ} \mathrm{C}\right)$ con persistencia del dolor en fosa ilíaca derecha, sin signos de irritación peritoneal.

El ultrasonido de control, practicado el día 16 del puerperio, mostró útero de 13,5 x 5,2 x 6 cm, eco endometrial de $7 \mathrm{~mm}$ y cuello abierto. Se observó una masa de ecogenicidad mixta de 5,6 x 3,5 cm en anexo izquierdo, con líquido libre en fondo de saco anterior.

$\mathrm{Al}$ examen genital se encontró cérvix permeable, útero subinvolucionado, masas anexiales bilaterales y abombamiento de los fondos de saco.

El día 17 del puerperio se practicó laparotomía encontrándose útero subinvolucionado con múltiples abscesos en el fondo y la cara anterior; trompas de Falopio engrosadas, sin abscesos; parametrios engrosados y celulitis pélvica que comprometía todo el fondo de saco anterior. Los demás órganos no mostraban anormalidades. Se practicó histerectomía total. La evolución postoperatoria fue satisfactoria.

$\mathrm{Al}$ examen macroscópico de la pieza quirúrgica se encontró útero de $11 \times 9 \times 5 \mathrm{~cm}$ con peso de 320 g. Sobre la cara anterior y los bordes laterales se encontraron varias formaciones nodulares de color blanco-amarillento y aspecto hemorrágico con diámetros que oscilaban entre 3 y $4 \mathrm{~cm}$, algunas de las cuales eran friables (gráfica 1). Al corte se encontraron lesiones miometriales similares de 0,3 a 0,6 cm de diámetro (gráfica 2). 
El examen microscópico mostró múltiples colecciones purulentas intramurales sin reacción inflamatoria aguda, ni necrosis en el miometrio circundante e infiltrado linfoplasmocitario y perineural miometrial, compatibles con abscesos. También se encontró endometritis y endocervicitis crónicas inespecíficas.

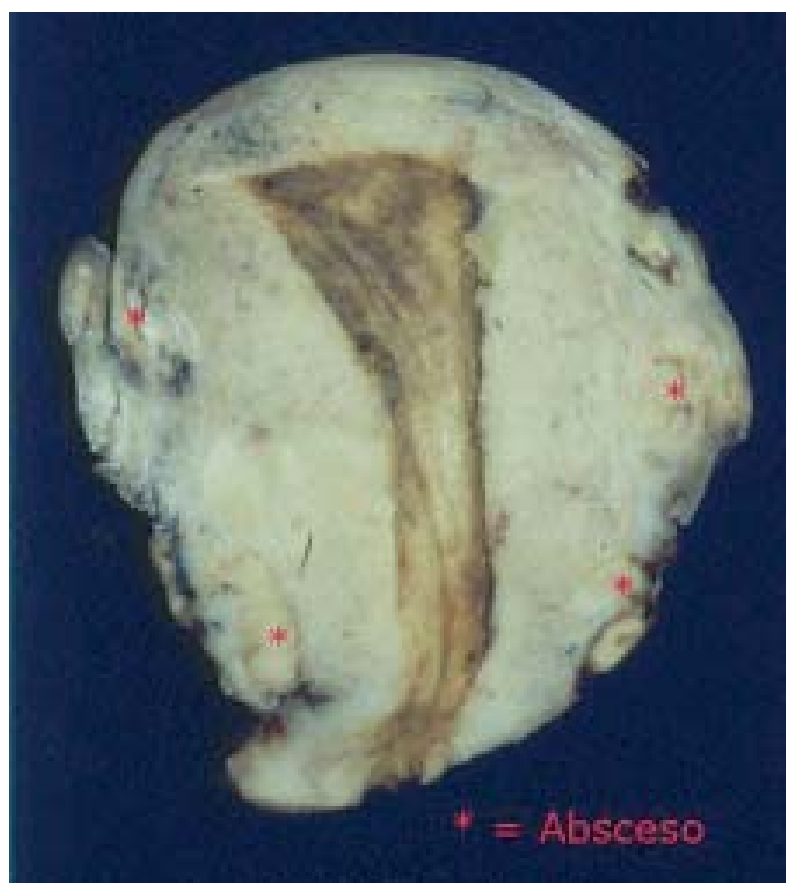

Gráfica 1. Aspecto macroscópico del útero en corte coronal que muestra múltiples abscesos en la cara anterior y los bordes laterales (señalados con asteriscos).

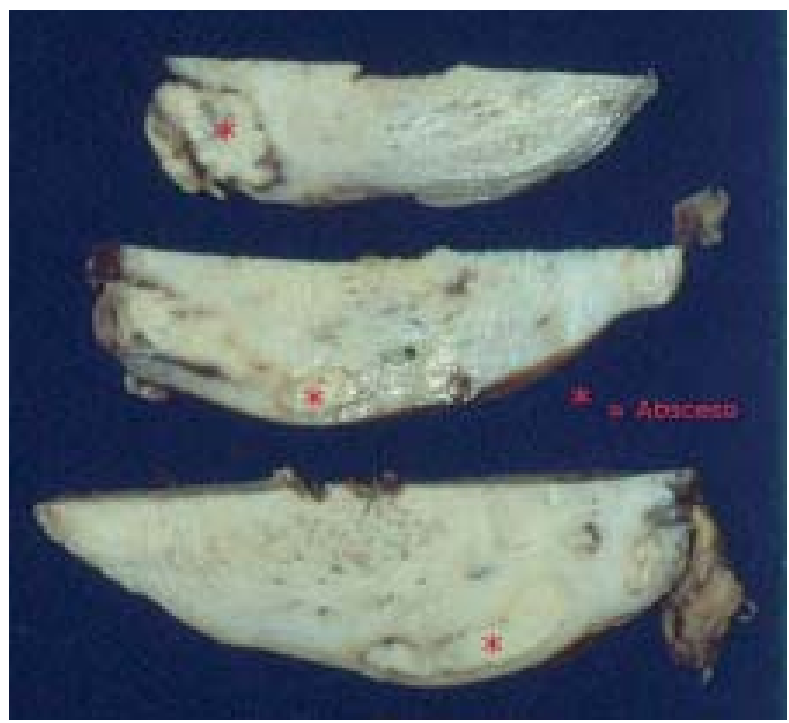

Gráfica 2. Cortes a través de las paredes uterinas que muestran múltiples abscesos a nivel del miometrio (señalados con asteriscos).

\section{Consideraciones éticas}

Para esta publicación se protegió la confidencialidad de la paciente; las fotos que aparecen corresponden a especímenes de patología que no revelan su identidad.

\section{DISCUSIÓN Y REVISIÓN}

\section{DE LA LITERATURA}

La infección uterina puerperal es una complicación desafortunada del parto. La incidencia de infección uterina puerperal en el Instituto Materno infantil de Bogotá (centro ginecobstétrico de tercer nivel) es de 4 a $9 \%$ después de parto vaginal y de 6 a 10\% postcesárea. Clínicamente se caracteriza por signos de respuesta inflamatoria sistémica (taquicardia, polipnea, fiebre, leucocitosis, neutrofilia), acompañados de signos locales tales como subinvolución y dolor uterinos, cérvix permeable y loquios turbios o fétidos. El diagnóstico de infección uterina puerperal requiere como mínimo tres de los criterios anteriores, incluyendo por lo menos un signo local.

La clasificación de la infección uterina puerperal se muestra en la tabla 1 .

La infección más frecuente es la endometritis y un $2 \%$ corresponden a miometritis. En la miometritis se observa un compromiso sistémico mayor, dado por sepsis severa persistente (disfunción de un órgano o

Tabla 1. Clasificación de la infección uterina puerperal según el compromiso anatómico del útero y de sus anexos.

\begin{tabular}{l} 
I. Limitada al útero \\
a. Endometritis. \\
b. Miometritis. \\
II. Compromiso de anexos y/o parametrios \\
\hline a. Salpingitis. \\
\hline b. Absceso tubo-ovárico. \\
\hline c. Celulitis pélvica y tromboflebitis pélvica séptica. \\
\hline III. Compromiso de peritoneo \\
\hline a. Pelviperitonitis \\
\hline b. Peritonitis
\end{tabular}


sistema), choque séptico o síndrome de disfunción orgánica múltiple (disfunción de dos o más órganos o sistemas). Estas pacientes responden inadecuadamente al tratamiento antibiótico, persistiendo los signos locales y sistémicos de infección. El útero puede ser doloroso y estar subinvolucionado. En algunos casos, la miometritis es seguida por tromboflebitis séptica de las venas uterinas y ováricas, la cual puede producir tromboembolismo pulmonar séptico.

Se ha demostrado que la infección uterina puerperal es ascendente en la gran mayoría de los casos. Los microorganismos colonizan la cavidad uterina en el puerperio, causando infección del endometrio y en la cesárea, infección de la histerorrafia. Alternativamente, algunos investigadores han encontrado que la miometritis puede estar presente en el momento de realizar la cesárea, incluso en pacientes asintomáticas.

Azziz y cols. estudiaron 91 pacientes a quienes les realizaron biopsias de placenta y de miometrio en el momento de la cesárea, encontrando evidencia histológica de corioamnionitis en 9 (10\%) y de miometritis aguda en 10 (11\%). Estos hallazgos fueron más frecuentes en pacientes con trabajo de parto o con ruptura de membranas mayor de 6 horas. ${ }^{1}$

Ustun y cols informaron que la presencia y profundidad de la infiltración endomiometrial por neutrófilos, se correlacionan significativamente con el intervalo de tiempo entre la ruptura de membranas y la terminación del embarazo. ${ }^{2}$ A las 6 horas de la ruptura de membranas el líquido amniótico se encuentra colonizado por bacterias. Los aislamientos consisten en una flora polimicrobiana de bacterias anaerobias y aerobias. Las pacientes con dicha colonización pueden desarrollar posteriormente una endomiometritis puerperal. ${ }^{3,4}$

En un estudio de casos y controles, Libombo investigó los factores socioeconómicos y la historia obstétrica anterior y del embarazo actual, encontrando los siguientes factores de riesgo para endomiometritis postparto vaginal: bajo peso al nacer (OR 16,55); parto pretérmino (OR 10,07); morbilidad neonatal grave (OR 14,27); historia de mortinatos $(\mathrm{OR} 9,44)$ y antecedente de parto con feto de bajo peso al nacer (OR 3,9). Las pacientes infectadas tenían con mayor frecuencia índice de masa corporal $<22,5(\mathrm{OR} 3,41)$ y hemoglobina $<$ $10 \mathrm{~g} / \mathrm{dl}(\mathrm{OR} 3,12) .{ }^{4}$ En las pacientes con infección postcesárea los factores socioeconómicos y obstétricos estuvieron distribuidos similarmente entre los casos y los controles, a excepción de un control prenatal que detectó mayores factores de riesgo en los casos (OR 3,29). ${ }^{5,6}$

Se ha descrito un tipo de infección fulminante por estreptococo del grupo A en pacientes obstétricas. La enfermedad ocurre en una etapa tardía de la gestación y es precedida de una infección del tracto respiratorio superior, la cual es seguida por bacteriemia e infección miometrial hematógena, con el desarrollo de miometritis purulenta aguda. Se presenta shock séptico y disfunción orgánica múltiple. El pronóstico es malo, tanto para la madre, como para el feto. Este tipo de infección comienza antes del parto, sin evidencia de infección bacteriana ascendente del canal del parto. ${ }^{7}$

Se han informado algunos casos de abscesos intramiometriales como complicación de la gestación. Fung y cols. presentaron dos pacientes quienes ingresaron en trabajo de parto a término. En el expulsivo se detectó sufrimiento fetal y se les practicó cesárea. En ambos casos se encontró un absceso de 3 a $4 \mathrm{~cm}$ de diámetro a nivel del miometrio, el cual fue drenado. Las pacientes recibieron adicionalmente antibióticos y evolucionaron satisfactoriamente. ${ }^{8}$

En la revisión de la literatura acerca de abscesos miometriales en el puerperio no se logró identificar casos similares al descrito en este artículo. Consideramos que nuestra paciente presentó una infección uterina puerperal que comprometió el endometrio y el miometrio. Probablemente debido al manejo de soporte hemodinámico intensivo, a la terapia antibiótica de amplio espectro y a los mecanismos inmunológicos de defensa de la paciente, la infección miometrial se localizó en forma de abscesos en lugar de la presentación usual de miometritis diseminada aguda, que se informa en la literatura. 


\section{REFERENCIAS}

1. Azziz R, Cumming J, Naeye R. Acute myometritis and chorioamnionitis during cesarean section of asymptomatic women. Am J Obstet Gynecol 1988;159:1137-9.

2. Ustun C, Kokcu A, Cil E, Kandemir B. Relationship between endomyometritis and the duration of premature membrane rupture. J Matern Fetal Med 1998;7:243-6.

3. Gilstrap LC 3rd, Cunningham FG. The bacterial pathogenesis of infection following cesarean section. Obstet Gynecol 1979;53:545-9.

4. Libombo A, Folgosa R, Bergstrom S. Risk factors in puerperal endometritis-myometritis. An incident casereferent study. Gynecol Obstet Invest 1994;38:198-205.

5. Libombo A, Folgosa R, Bergstrom S. A case-control study on post-cesarean endometritis-myometritis in Mozambique. Gynecol Obstet Invest 1995;39:1805.

6. Bergstrom S, Libombo A. Low birthweight and post partum endometritis-myometritis. Acta Obstet Gynecol Scand 1995;74:611-3.

7. Ooe K, Udagawa H. A new type of fulminant group A streptococcal infection in obstetric patients: report of two cases. Hum Pathol 1997;28:509-12.

8. Fung TY, Yim SF, Fung HYM. Intramiometral abscess complicating pregnancy. J Reprod Med 1998;43:1002-4.

Conflicto de intereses: ninguno declarado. 